\title{
Frutas frescas e corpos quebrados na fronteira da antropologia médica
}

\author{
Fresh fruit and broken bodies on the frontier of \\ medical anthropology
}

\author{
Frutas frescas y cuerpos rotos en la frontera de la \\ antropología médica
}

CORPOS RESISTENTES. IMIGRAÇÃO, RACISMO E TRABALHO AGRÍCOLA NOS EUA. Holmes S. Odivelas: Editora Outro Modo/Le Monde Diplomatique; 2019. 376 p. ISBN: 978-98954095-8-7.

doi: 10.1590/0102-311X00067121

Em sua edição de 2020, a Reunião Brasileira de Antropologia teve como conferencista convidado Seth Holmes, professor de Antropologia Médica e Saúde Pública na Universidade da Califórnia, Berkeley, Estados Unidos. Na ocasião, o médico e antropólogo apresentou uma síntese de seu premiado livro, Fresh Fruits, Broken Bodies: Migrant Farmworkers in the United States, recentemente traduzido e publicado em edição portuguesa com o título contundente de Corpos resistentes, mas que suprime o contraste do título original, cuja referência a frutas frescas e corpos quebrados sintetiza o dilema abordado no livro. Como destacado no prefácio de Philippe Bourgois, a valorização crescente do bem-viver associado ao consumo de produtos saudáveis pelos americanos não raro oblitera as péssimas condições de vida de trabalhadores - sobretudo estrangeiros cuja cidadania não é reconhecida - que se curvam nos campos para a colheita de morangos, framboesas, maçãs e outras frutas. Particularmente nesse livro, Holmes compartilha sua etnografia multissituada junto a famílias do povo indígena Triqui, que clandestinamente migram das montanhas de Oaxaca, no
México, para trabalhar em campos de frutas nos estados americanos de Washington e Califórnia.

O livro é estruturado em sete capítulos, cujos títulos, em sua maioria, incluem expressões ouvidas no trabalho de campo: (1) Vale a Pena Arriscares a Vida? introduz o problema, os contextos e as condições da pesquisa em seções alternadas com um relato sobre a travessia clandestina da fronteira entre México e Estados Unidos empreendida pelo autor com um grupo Triqui; (2) 'Nós Somos Trabalhadores do Campo': Antropologia Corporizada da Migração" aborda a questão migratória entre México e Estados Unidos, bem como a opção metodológica pela etnografia; (3) Segregação na Quinta: Hierarquias Étnicas no Trabalho centra foco na etnicidade como operador de diferenças e desigualdades numa quinta de cultivo de frutas no Estado de Washington; (4) 'Como Sofrem os Pobres': a Corporização do Contínuo de Violência parte de três casos de trabalhadores Triqui para apontar a violência estrutural, simbólica e política como nexo causal de adoecimentos; (5) Os Médicos não Sabem Nada centra foco em práticas e discursos envolvendo profissionais de saúde e pacientes Triqui; (6) Porque Eles São Mais Próximos do Chão: a Naturalização do Sofrimento Social aponta a normalização e invisibilização de injustiças e desigualdades sociais como aspecto da violência simbólica; (7) Para Além da Mudança e da Solidariedade Pragmática, que corresponde à conclusão da obra, traz exemplos de solidariedade e mobilização envolvendo diferentes atores como horizontes de possibilidades no enfrentamento do racismo, da privação de direitos e ou- 
tras adversidades enfrentadas pelos Triqui desde o nível local, nas quintas, até questões globais sobre imigração laboral.

Holmes define seu trabalho como uma antropologia corporizada da migração. E podemos assim reconhecê-la em uma dupla acepção. A primeira remete ao próprio corpo do antropólogo como ferramenta metodológica para aproximar-se da perspectiva de seus interlocutores. Em várias frentes, Holmes buscou experimentar no corpo as consequências das desigualdades sociais que incidem nos corpos dos Triqui. O autor viveu em uma comunidade Triqui na região de Oaxaca e acompanhou um grupo na travessia clandestina da fronteira do México para os Estados Unidos, quando acabaram presos no deserto. Holmes também acompanhou famílias Triqui em deslocamentos entre diferentes campos de frutas nos estados de Washington e Califórnia, hospedando-se com eles em espaços precários e cumprindo jornadas exaustivas de colheita sete dias por semana, que rendiam pouco dinheiro e muitas dores no corpo. Em razão destas, Holmes acompanhou vários Triqui em consultas médicas, nas quais testemunhou práticas negligentes e discursos racistas por parte dos profissionais de saúde, em que adoecimentos eram atribuídos a supostas características pessoais e culturais dos pacientes.

Aqui chegamos à segunda acepção de antropologia corporizada no livro. Além de recurso metodológico e ético do pesquisador, o corpo é também lócus de investigação do problema de pesquisa, particularmente o adoecimento e seus nexos sociais. Acompanhando os Triqui na busca de tratamento por dores nos joelhos, na cabeça, no estômago, entre outras advindas de más condições de trabalho e de vida, a pesquisa se insere no campo da antropologia médica, bastante consolidado nos Estados Unidos e pujante nas universidades californianas. Holmes dialoga com diversos autores proeminentes neste campo, como Paul Farmer, Arthur Kleinman e Nancy Scheper-Hughes.

Particularmente, a ênfase analítica de Kleinman 1 em percepções e exegeses dos pacientes, assim como de Farmer 2,3 na incidência de estruturas sociais no adoecimento, são inflexionadas para os profissionais de saúde no capítulo 5 do livro de Holmes. A começar pelo olhar clínico, no sentido foucaultiano ${ }^{4}$, que eclipsa outras dimensões da pessoa ao centrar foco no que aparece em exames e outros dispositivos biomédicos. Holmes também analisa como muitos desses profissionais vinculam patologias e adversidades a costumes ou supostas predisposições culturais de indígenas ou de latino-americanos em geral. De modo análogo, o capítulo 3 centra foco em discursos, valores e práticas dos proprietários e funcionários que ocupam postos acima dos Triqui em uma quinta onde Holmes fez trabalho de campo (e trabalhou no campo).

Em sua análise, tanto na hierarquia laboral da quinta como nas instituições de saúde, especificidades e atores locais estão condicionados por estruturas sociais que ensejam injustiças, preconceitos e desigualdades. Por exemplo, dificuldades econômicas das quintas menores diante da hegemonia crescente de grandes corporações no mercado de alimentos, ou leis e dinâmicas institucionais que dificultam a atuação de profissionais de saúde, conferem maior complexidade aos contextos abordados, estendendo o foco para além das visões estereotipadas e atitudes racistas de atores locais.

Além da referência a autores que remetem a dimensões estruturais da violência, como Farmer ${ }^{2}$, Scheper-Hughes \& Bourgois 5 ou Bourgois 6 , o conceito de violência simbólica de Pierre Bourdieu 7,8 é central no livro. Como engrenagem social que incorre na invisibilização, incorporação e naturalização de desigualdades e injustiças, a violência simbólica ganha contornos na análise sociológica, trazendo à cena o que os atores envolvidos são incapazes de perceber ou formular.

O livro tem o mérito de não incorrer em visões exotizantes e reificadoras dos Triqui, tampouco dos funcionários da quinta ou dos profissionais de saúde. Entretanto, a embocadura bourdieusiana por vezes restringe possibilidades de que o campo desestabilize categorias analíticas. Por exemplo, a afirmação de alguns Triqui de que seus corpos são mais fortes do que os dos americanos em relação aos pesticidas (p. 302), razão pela qual podem suportá-los na colheita das frutas, é interpretada como um exemplo de violência simbólica que reforça a submissão desses trabalhadores a condições adversas. Entretanto, uma aposta analítica que buscasse adensar a perspectiva dos Triqui talvez pudesse nos inter- 
pelar com outras conceituações de corpo, de violência e do campo de forças que ela produz.

Holmes, contudo, não toma para si a vantagem epistêmica de definir o que é realidade e o que são representações sobre ela. Há um reiterado exercício autorreflexivo do antropólogo diante de seus aprendizados com os Triqui. Recusando uma posição supostamente heroica na travessia da fronteira, Holmes ressalva como sua prisão, a despeito de assustadora, foi abreviada em razão de sua cidadania americana e dos fins de pesquisa que a motivaram. $\mathrm{O}$ mesmo em relação à moradia precária e colheita exaustiva de frutas, em que o fato de ser um trabalho de campo fazia toda diferença em relação ao trabalho no campo para aqueles que dele dependiam. Ainda, o autor elabora uma bonita reflexão sobre a demanda por privacidade que se fez visível como singularidade cultural diante do estranhamento dos Triqui quando o antropólogo optou por dormir num roupeiro, que mal comportava seu corpo, em vez de estender seu colchão nos cômodos coletivos de um apartamento que alugaram conjuntamente.

$\mathrm{Na}$ fronteira da antropologia médica, a escrita acurada e vibrante de Holmes nos aproxima de trabalhadores cujas dores são negligenciadas por um Estado que recusa seus direitos, mas não prescinde de seus serviços. Os corpos quebrados de indígenas mexicanos são eclipsados nos mercados americanos onde se vendem frutas frescas e slogans saudáveis. A força e o mérito desse livro estão no deseclipsamento dessas injustiças e da complexidade social em que elas se assentam.

Valéria Mendonça de Macedo 1

1 Universidade Federal de São Paulo, Guarulhos, Brasil. vmacedo@unifesp.br

\section{Informação adicional}

ORCID: Valéria Mendonça de Macedo (0000-00029874-3333).

1. Kleinman A. The ilness narratives: suffering, healing, and the human condition. New York: Basic Books; 1998.

2. Farmer P. On suffering, and structural violence. A view from below. In: Kleinman A, Das V, Lock M, editors. Social suffering. Berkeley: University of California Press; 1997. p. 261-83.

3. Farmer P. Infections and inequalities: the modern plagues. Berkeley: University of California Press; 1999.

4. Foucault M. The birth of the clinic. New York: Vintage Press; 1994.

5. Scheper-Hughes N, Bourgois P. Introduction: making sense of violence. In: Scheper-Hughes N, Bourgois P, editors. Violence in war and peace. An anthology. Madden: Blackwell; 2003. p. $1-31$.

6. Bourgois P. The power of violence in war and peace: post-cold war lessons from El Salvador. Ethnography 2001; 2:5-34.

7. Bourdieu P. Meditações pascalianas. Rio de Janeiro: Bertrand Brasil; 2001.

8. Bourdieu P. Gender and symbolic violence. In: Scheper-Hughes N, Bourgois P, editors. Violence in war and peace. An anthology. Madden: Blackwell; 2003. p. 339-42. 